\title{
Diagnostic Characteristics of Urine Microscopy in Detecting Asymptomatic Bacteriuria of Pregnancy Using Urine Culture as Gold Standard.
}

\author{
Aiyebelehin Oyetayo Alfred ${ }^{1}$, Obazee $\mathrm{Matie}^{2}$, Sule Abdullateef Gbenga ${ }^{1}$, Ike \\ Chiedozie ${ }^{3}$, Duru U. Martin ${ }^{4}$. \\ ${ }^{1}$ Department of Family Medicine, Ahmadu Bello University Teaching Hospital, Zaria, ${ }^{2}$ Department of Family \\ Medicine, Ecos Hospital Benin City, ${ }^{3}$ Department of Public Health, Irrua Specialist Teaching Hospital, Irrua, ${ }^{4}$ \\ Department of Medical Microbiology, Faith Mediplex, Benin City, Nigeria.
}

\begin{abstract}
Objective: The objective of the study was to evaluate the diagnostic characteristics of urine Microscopy in detecting asymptomatic bacteriuria of pregnancy .

Methods: It was a descriptive, cross-sectional study involving 240 pregnant women who presented in the course of antenatal care from January to April 2009.

With the aid of a questionnaire patients who were recruited for the study had their socio-demographic data and relevant gynaecological and drug history recorded. A physical examination was done to document temperature, height, weight and symphysiofundal height. A clean-catch mid-stream urine sample was collected for microscopy and culture. White blood cell count of $\geq 5 / \mathrm{hpf}$ and/or bacteria count of $\geq 1 / \mathrm{hpf}$ of urine was considered significant for urine microscopy and a single colony count of $\geq 10^{5} / \mathrm{ml}$ from two consecutive urine samples was considered significant for urine culture.

Results: Using urine culture as gold standard, the sensitivity of urine microscopy was $90.9 \%$, the specificity was $49.3 \%$, the positive predictive value was $22.2 \%$ and the negative predictive value was $97.1 \%$.

Conclusion:Specificity of urine microscopy is very low. However, its high negative predictive value makes urine microscopy useful in ruling out bacteriuria in resource-poor settings.
\end{abstract}

Keywords: Asymptomatic bacteriuria, Urinary tract infection, urine microscopy, pregnant women

\section{Introduction}

Asymptomatic bacteriuria (ASB) is defined as the persistent bacterial colonization of the urinary tract in the absence of specific symptoms. It is the presence of more than $10^{5}$ Organisms per milliliter of urine in two urine culture samples in the absence of presenting symptoms. ${ }^{1,2,3}$ Untreated asymptomatic bacteriuria is a risk factor for acute cystitis and pyelonephritis in pregnancy ${ }^{4}$. Randomized control trials and cohort studies have shown that detection and treatment of ASB can decrease the occurrence of intrauterine growth retardation and also decrease incidence of preterm delivery and low birth weight ${ }^{4}$. Identification and treatment of ASB will lead to a ten-fold decrease in the occurrence of acute pyelonephritis later in pregnancy.

The decision on how to screen asymptomatic women for bacteriuria is a balance between the cost of screening versus the sensitivity and specificity of each test. The gold standard for detection of bacteriuria is urine culture but the test is costly and takes $24-48$ hours to obtain result ${ }^{2}$. The accuracy of faster screening methods (for example, leukocyte esterase dipstick, nitrite dipstick, urinalysis and Gram staining) have also been evaluated ${ }^{5}$. The increased number of false negatives and the relatively poor predictive value of positive test make the faster methods less useful ${ }^{2,6}$. In many developing countries, financial constraint may restrict the feasibility of introducing general screening of all pregnant women. The high laboratory charges of urine culture make it less cost-effective for routine screening in populations that have a low prevalence of ASB. Facilities to culture bacteria from mid-stream clean-catch urine sample in each trimester are still considered the best diagnostic test available in all settings?

\section{Methodology}

This cross-sectional study was carried out in the antenatal clinic of Faith Mediplex Benin City, SouthSouth Nigeria from January $15^{\text {th }}$ to April $14^{\text {th }}$, 2009. It was approved by the Ethical Committee of Faith Mediplex. All pregnant women attending antenatal clinic during the study period and who consented to participate in the study by signing a prepared consent form were clinically evaluated to exclude signs and symptoms of UTI. Other exclusion criteria were women with diabetic mellitus, sickle cell anaemia, urinary fistulae, significant vaginal discharge as well as women who had taken antibiotics in the previous two weeks. 
With the aid of a questionnaire, demographic features including age, parity, level of education, family income, marital status and gestational age of pregnancy were collected from the 240 pregnant women recruited for the study.

After being instructed on the correct mode of self collection of urine sample, they were provided with sterile universal bottles. Samples of 10-15ml urine were obtained. It was microscopically examined for pus cells and bacteria, and then cultured within two hours. Samples were cultured on dried plates of Blood agar and MacConkey agar for bacterial growth, using a calibrated loop delivering $0.002 \mathrm{ml}$ of urine. The microscopic examination as well as culture of the urine samples was done by one and the same medical laboratory scientist. Plates were incubated aerobically at $37^{\circ} \mathrm{C}$ overnight. Colony counts yielding pure bacterial growth of $10^{5}$ or more of bacteria per $\mathrm{ml}$ of voided urine aseptically collected from two consecutive samples were deemed significant. In this study the set criteria for diagnosing ASB in pregnancy by urine microscopy was five or moreWBC/HPF and/or one or more bacteria seen per high power field.

\section{Results}

From the study, the prevalence of ASB was $13.8 \%$ by urine culture and $43.8 \%$ by urine microscopy among antenatal clients in Faith Mediplex, Benin City. As noted in table 2 there is a higher percentage of multiparous women who had significant bacteriuria compared to the primigravid ones. Also table 2 showed that higher percentage of women in their second and third trimester had significant bacteriuria than those in first trimester.

Using urine culture as a gold standard, the sensitivity of urine microscopy was $90.9 \%$, the specificity was $49.3 \%$, the positive predictive value was $22.2 \%$ and the negative predictive value was $97.1 \%$. \{Table 3 \}

Table 1: Demographic characteristics of the participants

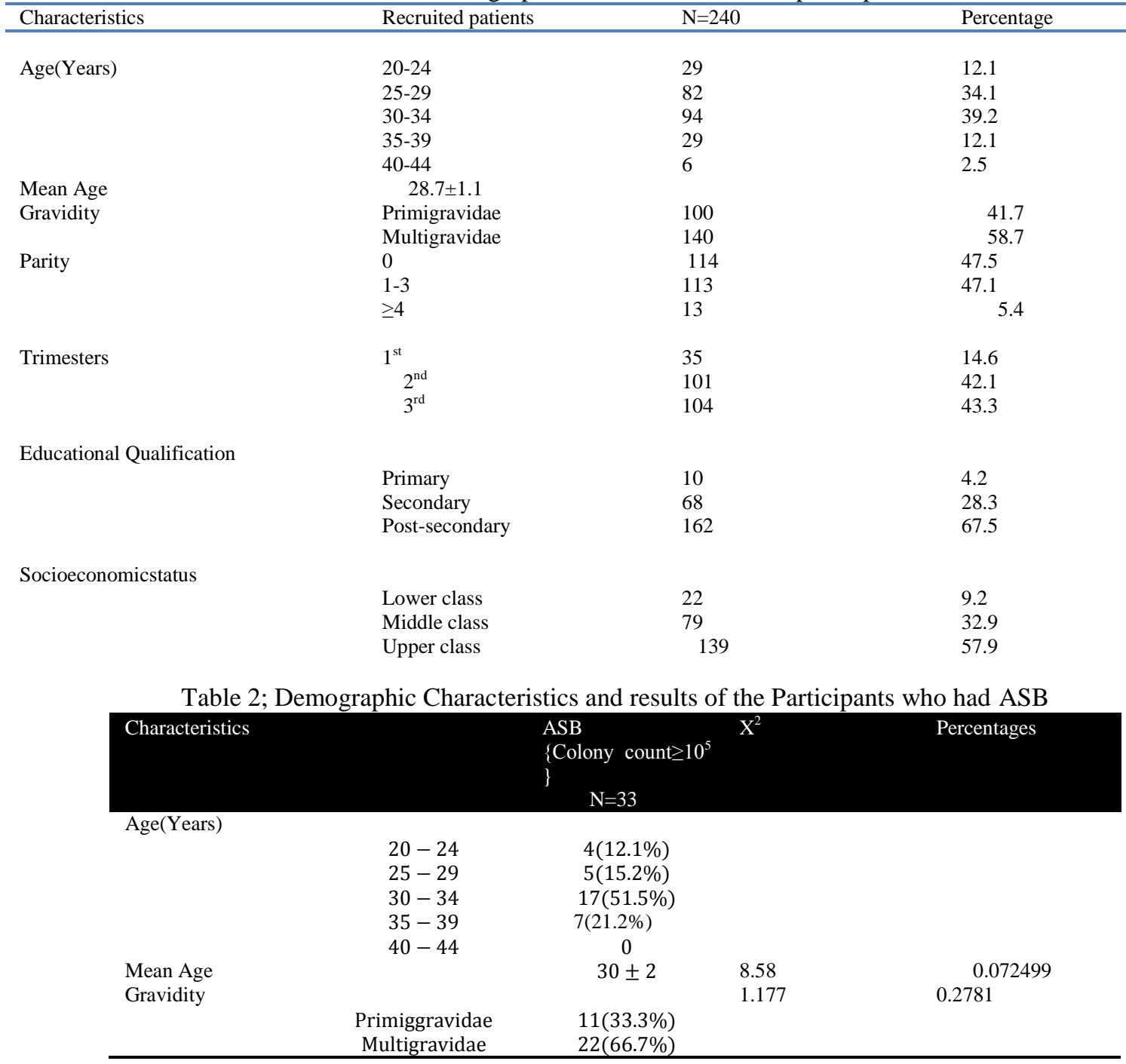




\begin{tabular}{|c|c|c|c|c|}
\hline Parity & $\begin{array}{c}1 \\
1-3 \\
\geq 4\end{array}$ & $\begin{array}{l}14 \\
17\end{array}$ & 0.31 & 0.8555 \\
\hline Trimesters & $\begin{array}{l}1^{\text {st }} \\
2^{\text {nd }} \\
3^{\text {rd }}\end{array}$ & $\begin{array}{l}2(6.1 \%) \\
16(48.5 \%) \\
15(45.5 \%)\end{array}$ & 2.32 & 0.313486 \\
\hline $\begin{array}{l}\text { Educational } \\
\text { Qualification }\end{array}$ & & & 1.63 & 0.442639 \\
\hline & $\begin{array}{l}\text { Primary } \\
\text { Secondary } \\
\text { Post-secondary }\end{array}$ & $\begin{array}{l}1(3 \%) \\
12(36.4 \%) \\
20(60.6 \%)\end{array}$ & & \\
\hline $\begin{array}{l}\text { Socio-economic } \\
\text { Status }\end{array}$ & $\begin{array}{l}\text { Lower class } \\
\text { Middle class } \\
\text { Upper class }\end{array}$ & $\begin{array}{l}5(15.2 \%) \\
14(42.4 \%) \\
14(42.4 \%) \\
\end{array}$ & 4.16 & 0.12493 \\
\hline
\end{tabular}

Table 3 - Sensitivity, Specificity, Predictive values \& Accuracy of simple urine Microscopy using urine culture as gold standard.

\begin{tabular}{|c|c|c|c|c|}
\hline \multirow{2}{*}{\multicolumn{2}{|c|}{$\begin{array}{l}\text { Significant urine microscopy } \\
(\geq 1 \text { bacteria } / \mathrm{hpf} \\
\& / \text { or } \geq 5 \mathrm{WBC} / \mathrm{hpf})\end{array}$}} & \multicolumn{3}{|c|}{$\begin{array}{l}\text { Significant growth on urine culture }(\geq \\
\left.10^{5} \mathrm{cfu} / \mathrm{ml}\right)\end{array}$} \\
\hline & & Yes No & & otal \\
\hline Yes & $\begin{array}{ll}30 & \mathrm{TP} \\
\end{array}$ & 105 F P & 135 & \\
\hline No & $3 \quad \mathrm{FN}$ & $102 \mathrm{TN}$ & 105 & \\
\hline Total & 33 & 207 & 240 & \\
\hline
\end{tabular}

$\mathrm{TP}=$ True positive, $\mathrm{FP}=$ False positive, $\mathrm{FN}=$ False negative, $\mathrm{TN}=$ True negative

$$
\begin{aligned}
\text { Sensitivity } & =\mathrm{TP} / \mathrm{TP}+\mathrm{FN} \\
& =30 / 30+3=90.9 \% \\
\text { Specificity } & =\mathrm{TN} / \mathrm{TN}+\mathrm{FP} \\
& =102 / 102+105=49.3 \%
\end{aligned}
$$

Negative Predictive Value NPV $=$ TN $/ \mathrm{TN}+\mathrm{FN}$

$$
=102 / 102+3=97.14 \%
$$

Accuracy $=\mathrm{TP}+\mathrm{TN} /$ Grand total

$$
=30+102 / 240=55 \%
$$

Positive Predictive Value PPV $=\mathrm{TP} / \mathrm{TP}+\mathrm{FP}$

$$
=30 / 30+105=22.22 \%
$$

\section{Discussion}

Using urine culture as a gold standard, the sensitivity of urine microscopy was $90.9 \%$, while the specificity was $49.3 \%$. The specificity of $49.3 \%$ is very low or it has high false positive rate in that $51.7 \%$ of women without ASB will need confirmatory testing with urine culture. This suggests that urine microscopy is not a very accurate method of diagnosing ASB as the specificity is less than $90 \%$. However, a negative predictive value of $97.1 \%$ means patients with negative test results are very unlikely to have the disease. These results are in agreement with a Turkish study ${ }^{8}$ where the sensitivity and negative predictive values of leukocyturia as a screening test for asymptomatic bacteriuria were $91.3 \%$, and $98.5 \%$, respectively but not with the work done in The United Arab Emirate and Tanzania where sensitivity of 67\% and38.9\% respectively were obtained $^{9,10}$. In this study white blood cell count of $\geq 5 / \mathrm{hpf}$ and/or bacteria count of $\geq 1 / \mathrm{hpf}$ of urine was considered significant for urine microscopy. This may account for the increase sensitivity. This significant level was adopted because in pregnancy, the consequence of an undiagnosed case of ASB far outweighs the cost of a false negative test. In a similar study where the significant level was further reduced to $\leq 2$ /hpf and $\leq 3 / \mathrm{hpf}$, the negative predictive value of $98.0 \%$ and $96.5 \%$ respectively in this particular study ${ }^{11}$ were similar to the values obtained in our own study. These findings underscore the fact that urine microscopy can be used to rule out bacteriuria as a negative test is reassuring that the patient does not have the disease. 
As noted in table 2 there is a higher percentage of multiparous women who had significant bacteriuria compared to the primigravid ones. Also table 2 showed that higher percentage of women in their second and third trimester had significant bacteriuria than those in first trimester. Though these findings are statistically insignificant, these can account for the role of recurrent UTI as well as the degree of gravidity in the prevalence of ASB. This was similar to the findings in the study by Akinola et $\mathrm{al}^{12}$.

Urinary tract infections occur commonly in pregnancy. Bacterial colonization may occur in the lower and upper urinary tract, and is facilitated by the normal physiologic changes of pregnancy. This is evident in our study as higher percentage of women in their second and third trimester had significant bacteriuria than those in their first trimester. This is so because of a combination of mechanical, hormonal and physiologic changes which have profound impact on the acquisition, and natural history of bacteriuria during pregnancy. The expanding uterus impinges on the ureters leading to urinary stasis (a culture medium for virulent microorganisms) with 'hydronephrosis and hydroureters of pregnancy' and uterine dextrorotation explains its tendency to occur more often on the right ureter ${ }^{13}$. The plasma levels of estrogenic, progesterone and prostaglandin-like agents increase in pregnancy. This causes the dilatation of the ureters and decrease in ureteric peristalsis and bladder tone leading also to urinary stasis even in the absence of obstruction during pregnancy ${ }^{14,15}$. Incompetence of the uretero-vesical valve also occurs due to the effect of these hormones, with the consequent vesicoureteral reflux of urine, increasing the susceptibility to infection. These changes usually occur from the sixth week of pregnancy, peaks during the $22^{\text {nd }}$ to $24^{\text {th }}$ week in approximately $90 \%$ of women and will remain until delivery ${ }^{14,15}$.

Asymptomatic bacteriuria, poses a serious threat to the mother and fetus. Optimal treatment regimens and preventive strategies continue to be investigated. More information is needed about the prevalence and pattern of ASB in different populations at different gestational ages, as well as the recurrence rates in those completing treatment. The fact that higher percentage of the multiparous women had asymptomatic bacteriuria in this study shows that the issue of recurrent infection is an important factor. The diagnostic characteristics like sensitivity and specificity of screening tests for ASB, which could be equal or better in diagnostic accuracy than quantitative urine culture, but less expensive or complex, is an area on which research efforts should also focus ${ }^{16}$.

The limitation of this study lies in the fact that the method of urine collection, mid-stream urine after cleaning the vulva with chlorhexidine swabs, is subject to what the patient did even after instruction on how to get the sample. Also it was not a randomized case/control study and so the strength of the study is limited.

\section{Conclusion and recommendation;}

There is a low accuracy and positive predictive value of leukocyturia or simple urine microscopy in the diagnosis of ASB of pregnancy. However, in resource-poor settings where facilities for urine culture are not readily available, the high negative predictive value of simple urine microscopy can be used to rule out bacteriuria since patient with negative test results are very unlikely to have the disease.

\section{References}

[1]. John ED, Michael L E. Urinary tract infection during pregnancy. AmFam Physician 2000; 61:713-21.

[2]. Smail F, Schnarr J Asymptomatic bacteriuria and symptomatic urinary tract infections in pregnancy.Eur J Clin Invest. 2008 Oct; 38 Suppl 2:50-7.

[3]. Stein G; Fünfstück R. Asymptomatic bacteriuria. Med Klin (Munich). 2000; 95(4):195-200.

[4]. Saidi A, Delaporte V, Lechevallier E. Urological problems encountered during pregnancy. Prog Urol. 2005; 15(1):1-5

[5]. Kacmaz B; Cakir O; Aksoy A; Biri A. Evaluation of rapid urine screening tests to detect asymptomatic bacteriuria in pregnancy. Jpn J Infect Dis. 2006; 59(4):261-3.

[6]. Kolstrup N, Vold C, Melbye H. Asymptomatic bacteriuria in pregnant women. TidsskrNorLaegeforen. 2003; 123(15):2027-8.

[7]. McIsaac W, Carroll JC, Biringer A, Bernstein P, Lyons E, Low DE, et al. Screening for asymptomatic bacteriuria in pregnancy. J ObstetGynaecol Can. 2005; 27(1):20-4.

[8]. Uncu Y, Uncu G, Esmer A, Bilgel N. Should asymptomatic bacteriuria be screened in pregnancy? ClinExpObstet Gynecol. 2002; 29(4):2815 .

[9]. Abdullah AA, Al-Moslih MI. Prevalence of asymptomatic bacteriuria in pregnant women in Sharajah. United Arab Emirates. East Mediterr Health J. 2005; 5(6): 1045- 52.

[10]. Masinde A, Gumodoka B, Kilonzo A, MshanaSE.Prevalence of urinary tract infection among pregnant women at Bugando Medical Centre, Mwanza, Tanzania. Tanzan J Health Res. 2009 Jul;11(3):154-9.

[11]. Gyang MD, Dankyau M, YohannaSMadaki A. Is Simple microscopy Useful in the Diagnosis of Asymptomatic Bacteriuria in Pregnancy in Primary Care Settings? Nigerian J FamPract. Nov 2012 ; 3 (1): 7-14.

[12]. Ajyi AB, Nwabuisi C, Aboyeji AP, Ajayi NS, Fowotade A, FakeyeOO. Asymptomatic Bacteriuria in Antenatal Patients in Ilorin, Nigeria. Oman Med J 2012 Jan; 27(1):31-35.

[13]. Delzell JE Jr, Lefevre ML. Urinary tract infections during pregnancy. Am Fam Physician 2000; 61: 713-21 [Erratum in 2000; 61: 3567].

[14]. Cutner, A., Cardozo, L.D. and Benness, C.J.: Assessment of urinary symptoms in early pregnancy, Br J ObstetGynaecol 1991; 98:12831286.

[15]. Rasmussen, P.E., Nielsen, F.R.: Hydronephrosis during pregnancy: A literature survey, Eur J ObstetGynecolReprodBiol 1988; $27: 249$.

[16]. Tolosa JE. Antibiotics for asymptomatic bacteriuria in pregnancy: RHL commentary (last revised: 14 January 2008). The WHO Reproductive Health Library; Geneva: World Health Organization. 